\title{
System dynamics leading to growth and development of a Tropical Cyclone over Indian Ocean: a brief review
}

\author{
M. Devi ${ }^{1}$, A. K. Barbara ${ }^{1}$ and A. Depueva ${ }^{2}$ \\ ${ }^{1}$ Department of Physics, Gauhati University, Guwahati 781014, Assam, India \\ ${ }^{2}$ Pushkov Institute of Terrestrial Magnetism, Ionosphere and Radio Wave Propagation. \\ Moscow, Troitsk, 142190, \\ *Email: md555gu@gmail.com
}

\begin{abstract}
Starting with a brief background on growth and development of Tropical Cyclone (TC), the paper gives the basic science behind generation of TC over Indian Ocean covering the water mass from Bay of Bengal and Arabian Sea. A few devastating cyclones of past and recent days over this region are presented to highlight that the effects of TC crosses all political boundaries and far beyond its landfall zone. The write up also focuses on the global efforts in upgrading technology and approaches in prediction of cyclone -track and early warning methods to the hazard prone areas. The positive aspects of TC are also brought out in the discussion. The paper finally highlights the inherent danger of worldwide operation to contain the energy of a developing TC.
\end{abstract}

Keywords: tropical cyclone; track; prediction; hazards

\section{Introduction}

The tropical cyclone (TC) is a special state of weather situation of the zone encompassing the Tropic of Cancer and the Tropic of Capricorn (lat. $\pm 23^{\circ}$ to $\pm 2^{\circ}$ ). Some characteristics of this region that make its weather system unique from the rest of the globe are that it receives direct sun rays relative to higher latitude high latitudes, thereby maintaining an average annual temperature at a higher level and that in this tropical zone the Coriolis force which develops by rotation of earth cannot be neglected in this area [NOAA report 1999; Chandrasekar 2010]. As a consequence, an organized circulation of cloud will be generated over warm ocean bodies by a perturbation in the atmosphere. This circulatory cloud 
movement is accompanied by winds of varying magnitudes. The wind flows counterclockwise in the Northern Hemisphere and clockwise in the Southern Hemisphere.If magnitude of wind is less $63 \mathrm{~km} / \mathrm{h}$ a 'depression or low pressure zone' is developed over the sea surface. When the 'depression zone' receives a warm water surface and an atmosphere with no wind shear, a favourable situation is created for growth of strong winds greater than $63 \mathrm{~km} / \mathrm{h}$, the phenomenon is termed as tropical storm. If the phenomenon continues to grow further, the cyclic wind speed increases to $120 \mathrm{~km} / \mathrm{h}$ or beyond, than the situation is termed as tropical cyclone in Indian ocean, typhoon in western pacific and hurricane in eastern pacific or Atlantic. Such strong winds bring torrential rain and also generate high waves, known as storm surge that pushes the water to pile up above the normal sea level. Table I shows the index of severity of storm identified with wind speed.

Table I

Categorization of the storm type with wind speed

\begin{tabular}{|l|l|}
\hline $\begin{array}{l}\text { Definition /character of the severity of } \\
\text { storm }\end{array}$ & Wind speed \\
\hline Depression & $31-49 \mathrm{~km} / \mathrm{h}(17-27 \mathrm{knots})$ \\
\hline Deep Depression & $50-61 \mathrm{~km} / \mathrm{h}(28-33$ knots $)$ \\
\hline Cyclonic Storm & $50-61 \mathrm{~km} / \mathrm{h}(28-33$ knots $)$ \\
\hline Severe Cyclonic Storm & $88-117 \mathrm{~km} / \mathrm{h}(48-63$ knots $)$ \\
\hline Very Severe Cyclonic Storm & $\begin{array}{l}\text { (i) } 118-167 \mathrm{~km} / \mathrm{h}(64-90 \mathrm{knots}) \\
\text { (ii) } 168-221 \mathrm{~km} / \mathrm{h}(91-119 \mathrm{knots})\end{array}$ \\
\hline Super Cyclonic Storm & $\begin{array}{l}222 \mathrm{~km} / \mathrm{h} \text { and more }(120 \text { knots } \\
\text { and more })\end{array}$ \\
\hline
\end{tabular}

Along with the speed of wind, the severity of a storm is assessed from the pressure at the central position of circulatory structure of the cloud known as an eye. There is very little wind and rain, at this zone, in contrast to the violent conditions at the surrounding region where the wind is strongest. The pressure at the eye region is lowest but the temperature of air directly above it is warmer than the surroundings. From the cyclones structure, of Figure 1 (a), $1 \mathrm{~b}$ and 1(c) one can infer that the cyclone of Figure 1(a) is stronger compared to the other two. 


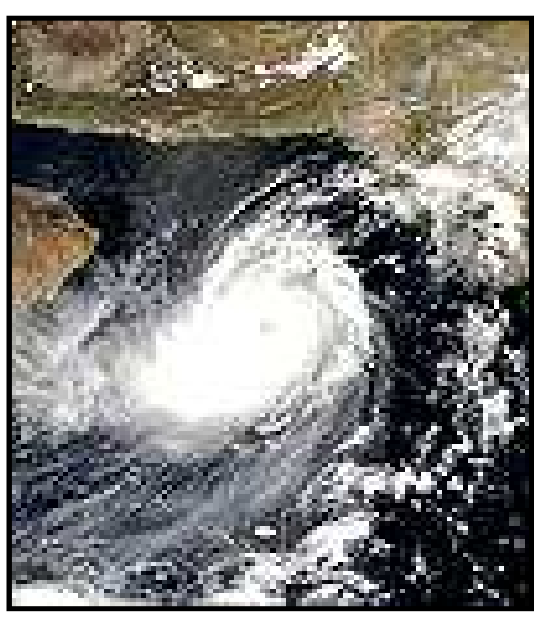

(a) Pressure: $920 \mathrm{mb}$

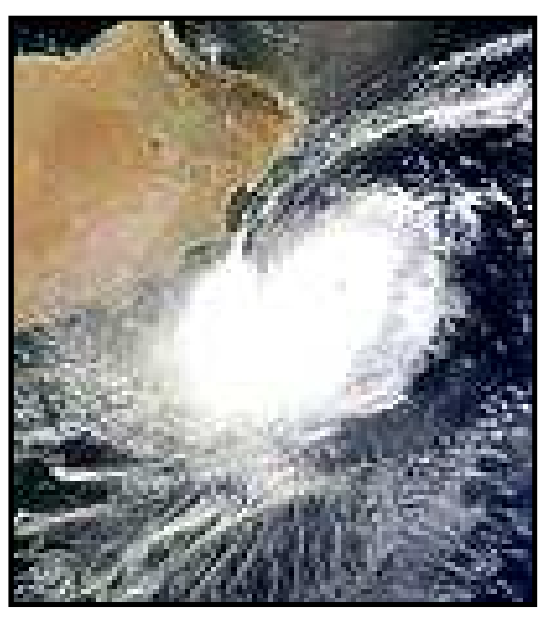

(b) Pressure: $970 \mathrm{mb}$

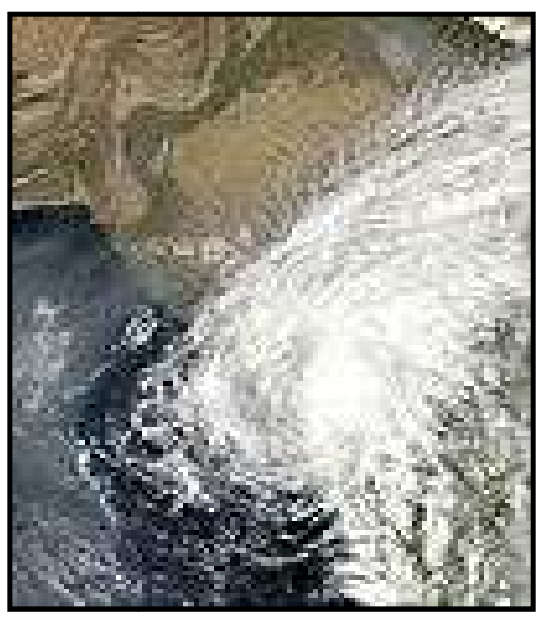

(c) Pressure: $988 \mathrm{mb}$

Figure 1 Shows that in (a) the pressure at the eye is lowest and hence the cyclone intensity will be higher compared to those other two cyclones shown in Figures (b) and (c).

Ranking of hurricanes or tropical cyclone by maximum sustained wind speed in Saffir-Simpson hurricane scale (SSHS), or the Saffir-Simpson hurricane wind scale (SSHWS) comes in five categories as shown in table II . In the lowest category 1, the tropical cyclone must attain sustained wind of at least $119 \mathrm{~km} / \mathrm{h}$ and in category 5, the strongest one, the sustained wind speed should exceed $251 \mathrm{~km} / \mathrm{h}$. Japan Meteorological Agency scale is used for defining magnitude of tropical cyclones in the Western Pacific though in many cases SSHS is preferred. The definition of sustained winds as recommended by the World Meteorological Organization (WMO) is used by most weather agencies that give 10-minute average wind at a height of $10 \mathrm{~m}$. However, definition also varies with oceanic basin. In India the sustained wind is measured in 3-minute averaging period, the Saffir-Simpson Hurricane Scale is based on wind speed measurements averaged over a 1-minute period, at $10 \mathrm{~m}$ height.

\section{Indian Ocean Cyclone}

The cyclones covered in this chapter will mainly be restricted to the ones over the basin of North Indian Ocean i.e., water bodies stretching from the Horn of Africa to in east to the west of the Malay Peninsula, the sea members in this zone are Arabian Sea (ARB) and Bay of Bengal (BOB).The area coverage is marked in Figure 2 by two arrow heads. 
Table II

Saffir-Simpson Hurricane Scale

\begin{tabular}{|c|c|}
\hline Category & Wind speed \\
\hline 1 & $\begin{array}{c}74-95 \mathrm{mph} \\
119-153 \mathrm{~km} / \mathrm{h}\end{array}$ \\
\hline 2 & $\begin{array}{c}96-110 \mathrm{mph} \\
154-177 \mathrm{~km} / \mathrm{h}\end{array}$ \\
\hline 3 & $\begin{array}{c}111-129 \mathrm{mph} \\
178-208 \mathrm{~km} / \mathrm{h}\end{array}$ \\
\hline 4 & $\begin{array}{c}130-156 \mathrm{mph} \\
209-251 \mathrm{~km} / \mathrm{h}\end{array}$ \\
\hline 5 & $\begin{array}{c}157 \mathrm{mph} \text { or higher } \\
252 \mathrm{~km} / \mathrm{h} \text { or higher }\end{array}$ \\
\hline
\end{tabular}

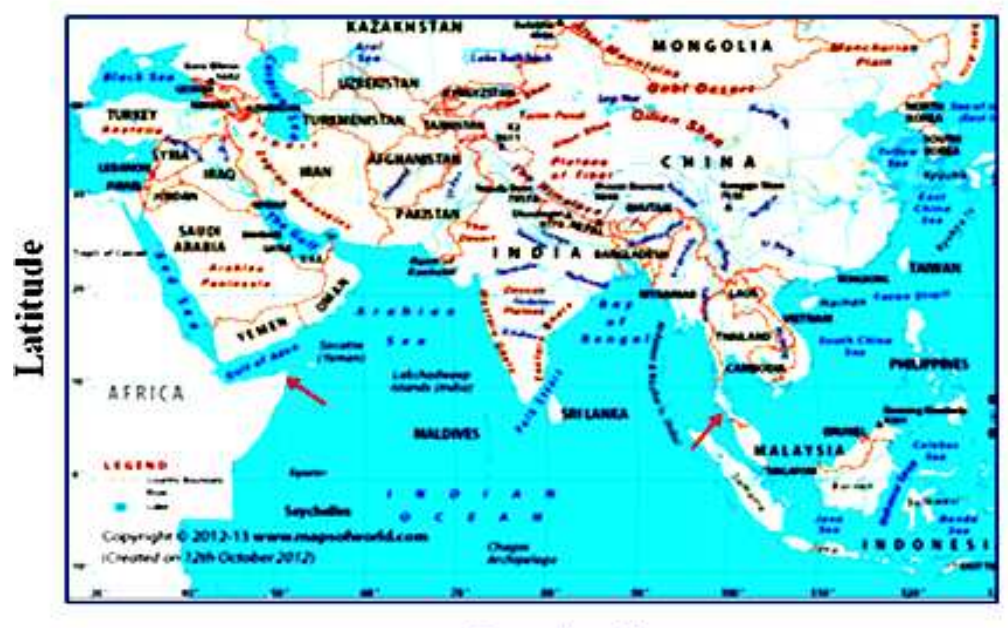

Longitude

Figure: 2 Two arrow heads one in the horn of Africa ( west ) and the other marked in Malay Peninsula to the east, cover the area over which cyclones are confined in the North Indian ocean. 


\subsection{Selection of names of tropical cyclones over north Indian Ocean.}

The procedure for naming cyclones has been laid down by the WMO and the United Nations Economic and Social Commission for Asia and the Pacific (ESCAP) and came into effect in 2004, though the practice of giving names to tropical cyclones began much earlier. The main aims of identifying a TC by a name are to provide an effective warning on the approach of a cyclone to the people of the possible endangered areas. The names are so selected that these are familiar to that particular region, but not to be named after any particular person and also not in alphabetic sequences.

The WMO/ESCAP Panel on TC at its twenty-seventh session held in 2000 in Muscat agreed to assign names to the tropical cyclones in the BOB and ARB. The eight countries entitled to name a cyclone are India, Bangladesh, Pakistan, Sri Lanka, the Maldives, Myanmar, Oman and Thailand. The Regional Specialised Meteorological Centre (RSMC) shown in Figure 3 are authorized to work in this scheme e.g., the RMSC New Delhi has to provide warning for an approaching TC formed in the North Indian Ocean and also to identify name to a cyclone. The names of the TC in the list are used sequentially, and they are not rotated every few years as are the practice followed for in Atlantic and Eastern Pacific zone cyclones.

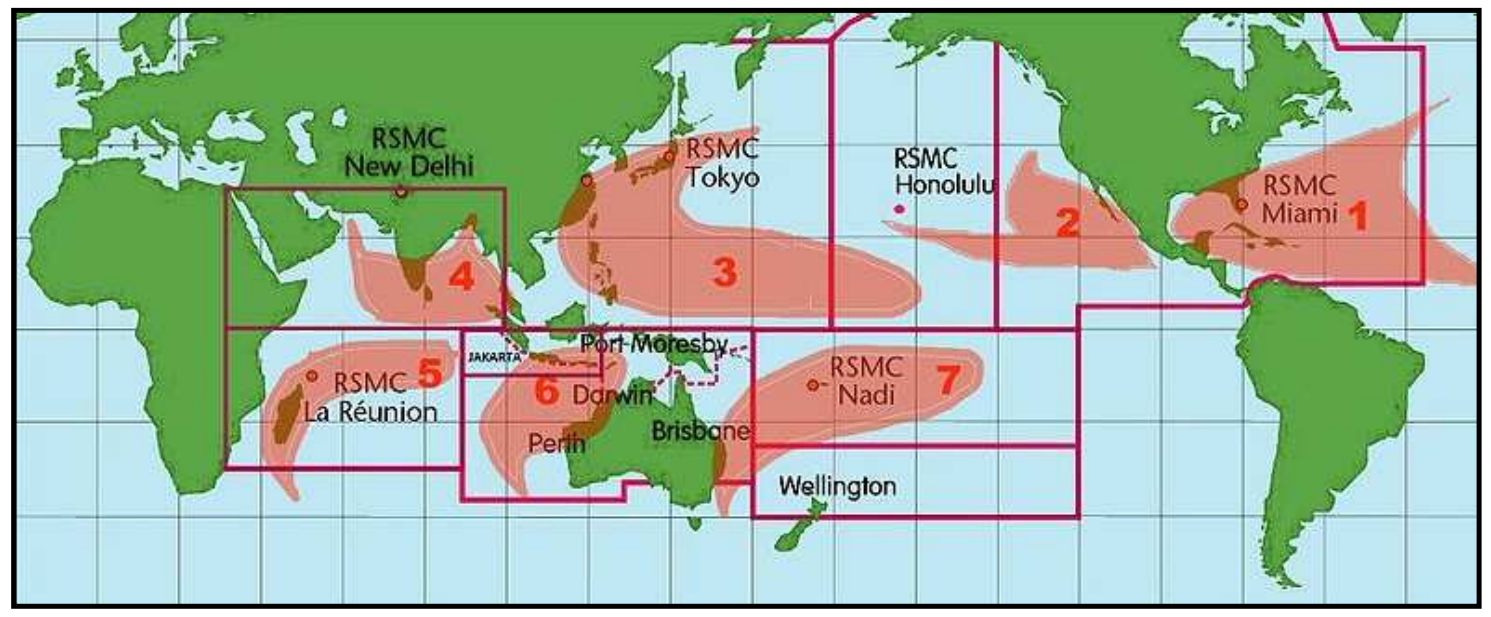

Figure .3. Areas of responsibility to different RSMCs. The zone 4, comes under the RSMC, New Delhi

The format of such a list of names of TC given by different countries within the jurisdiction of Zone 4 is presented in table III. The names of TC is used sequentially column wise starting from the first row of column one and continue to the last row of the last columns. Thus as an example it starts with Onil which follows Ogni, Hibaru, to...........Amphan. 
Table III

list of names given to TC by the countries covered under the Zone 4

\begin{tabular}{|c|c|c|c|c|c|c|c|c|}
\hline Bangladesh & Onli & Ogni & Nisha & Giri & Helen & Chapala & Ockhi & Fani \\
\hline India & Agni & Akash & Bijli & Lal & Lehar & Megh & Sagar & Vayu \\
\hline Maldives & Hibaru & Gonu & Aila & Keila & Madi & & & Hikaa \\
\hline Myanmar & pyarr & Yemyin & Phyan & Thane & Nanauk & Kyant & Daye & Kyarr \\
\hline Oman & Baaz & Sidr & Ward & Murjan & Hudhud & Nada & Luban & Maha \\
\hline Pakistan & Fannos & Nargis & Laila & Nilam & Nilofar & Vardah & Titli & Bulbul \\
\hline Sri Lanka & Mala & Rashmi & Bandu & Mahasen & Priya & Asiri & Gigum & Soba \\
\hline Thailand & Mukda & Khai & Phet & Phailin & Komen & Mora & Phethai & Amphan \\
& & Muk & Pet & & & & & \\
\hline
\end{tabular}

The number of cyclones that develop in the North Indian Ocean is only $7 \%$ of the global total, but their impact on the coasts is extremely severe mainly in the east coast. The TC could cause devastation when it landfalls in ocean shore, depending on the forces that steered it. One such factor is the higher latitude westerlies a wind set in the middle latitudes between $30^{\circ}$ and $60^{\circ}$ latitudes, blowing from the high pressure area towards the poles, which could move a TC back while crossing the subtropical ridge axis. The cyclone may be steered pole ward depending on increase of the Coriolis forces in that direction. The movement of a TC is called its track and an accurate track prediction necessitates the assessment of magnitude and wind flow pattern controlled by the pressure at the eye and its surrounding walls as the cyclone grows and dissipates.

\section{Cyclones over BOB and ARB .}

\subsection{Vulnerability of development of Cyclones over BOB and ARB}

As an example the track of the cyclone Giri presented in Figure 4(a), shows its growth in BOB (in October 20 ,2010) to fall in Myanmar (October 23). Hours before the landfall on October 22, Giri attained its peak intensity with sustained winds of $195 \mathrm{kmp} / \mathrm{h}$ and pressure of $950 \mathrm{mbar}$. It is put in 
Category 5 status with peak winds believed to have reached $250 \mathrm{~km} / \mathrm{h}$. the points in the track indicate location of the storm at an interval of 6- hours. The estimated devastation caused mainly to Myanmar and Bangladesh comes around \$359 million (in terms of 2010, US\$)

One more track of a TC named as Murjan (see the list in table III) developed on October 23, 2012 in ARB [ Figure 4(b)] shows that it was steered towards west to make its landfall on the Horn of Africa (on October 25,2012 . With $75 \mathrm{~km} / \mathrm{h}$ three minute sustained wind speed, Murjan was not a powerful TC.
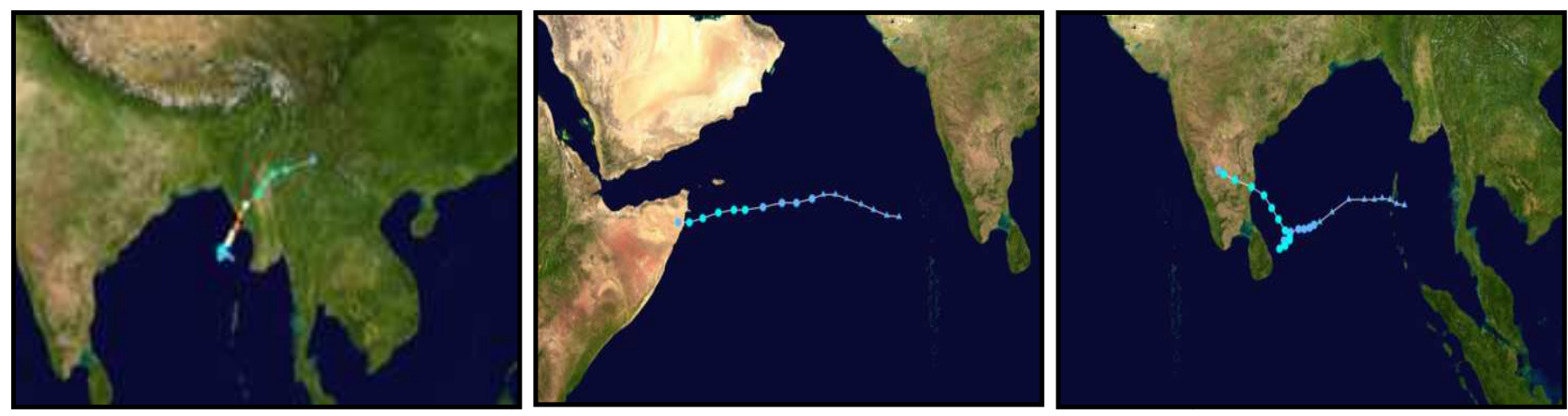

Figure: 4 Track of TC (a ) Giri developed in BOB, October 2010 (b) Murjan Developed in ARB, October 2012 and (c) Nilam, developed in South Central BOB on October 2012.

The track of another TC Nilam, shown in Figure 4 ( c ) developed as a weak tropical depression over south central BOB on October 27, 2012. It reached 3-minute peak sustained wind speeds of $85 \mathrm{~km} / \mathrm{h}$ during October 31, 2012 and continued to track northwestward under the influence of a low to mid-level subtropical ridge. Later that day the system made landfall on the South Indian Coast.

The cyclone-tracks generated over a period in the North Indian Sea shown in Figure 5 are indication of the vast area of invasion by cyclones, more by those developed over BOB, as also reported by others [Gray 1968; Dube et al., 1997 ; Singh et al., 2001]. Figure 6 also demonstrates the vulnerability of east coast to cyclone hazard is more serious compared to its west coast. The occurrence percentage of number of $\mathrm{TC}$ events in $\mathrm{BOB}$ may even exceed more than 100, at times, compared to these observed over ARB ( table IV ). 


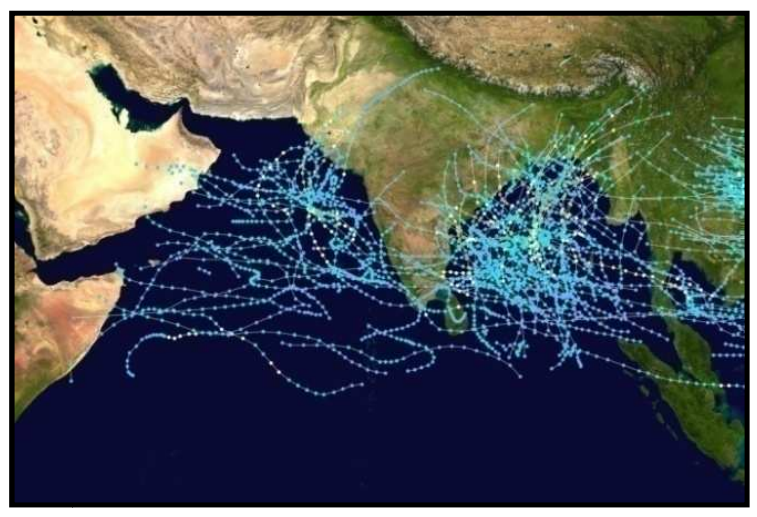

Figure .5. Tracks of cyclones developed in the Indian ocean over a period of time

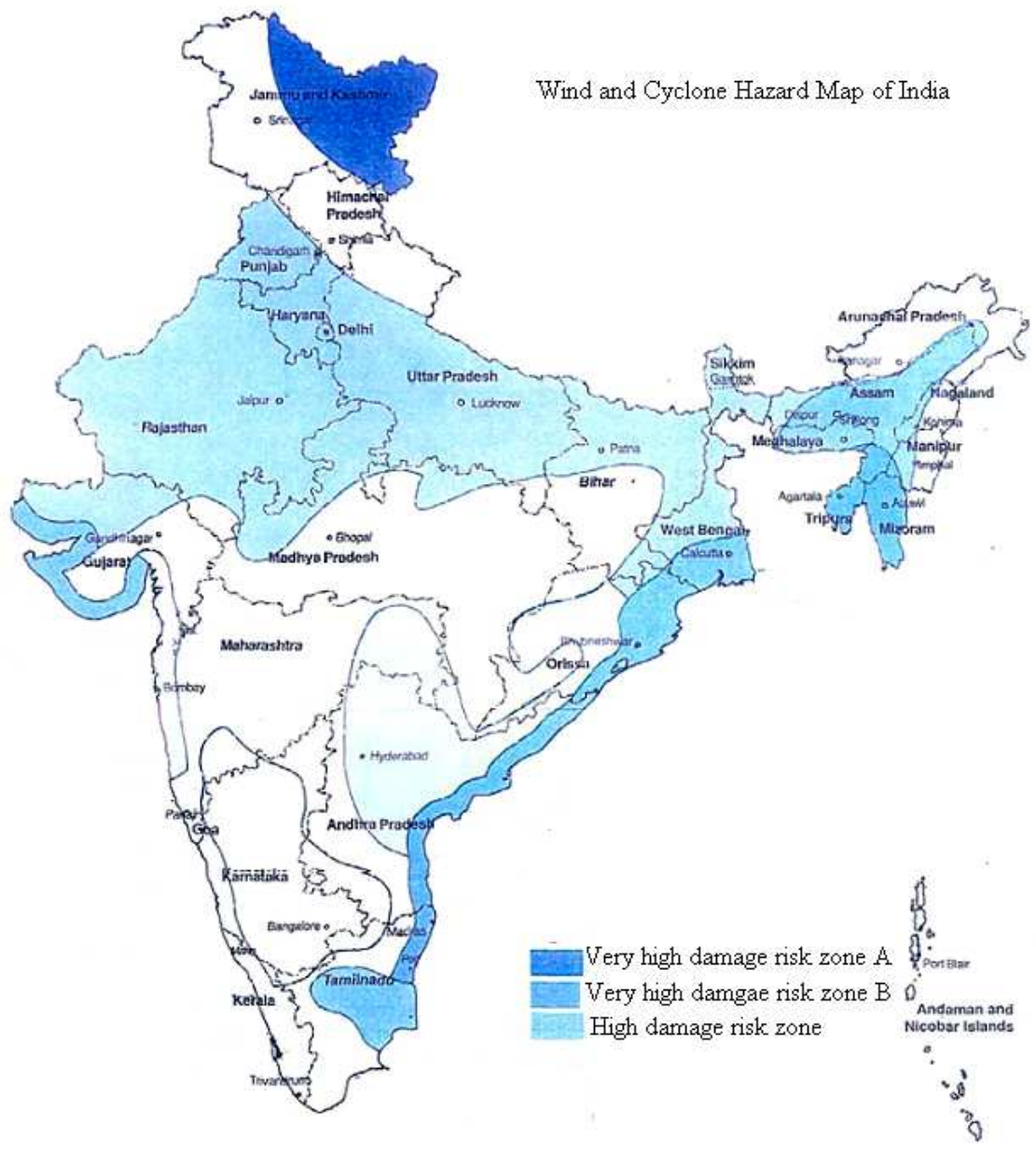

Figure .6. Wind and cyclone hazard map of India (source : http://www.ndmindia.nic.in) 
Table IV

A comparative assessment on frequency of generation of TC over BOB and ARB

\begin{tabular}{|c|l|l|l|l|l|l|l|l|l|l|}
\hline \multirow{2}{*}{$\begin{array}{c}\text { Storm } \\
\text { type }\end{array}$} & \multicolumn{9}{|c|}{ May } & \multicolumn{2}{c|}{ June } & \multicolumn{2}{c|}{ September } & \multicolumn{2}{c|}{ October } & \multicolumn{2}{c|}{ November } \\
\cline { 2 - 12 } & BOB & ARB & BOB & ARB & BOB & ARB & BOB & ARB & BOB & ARB \\
\hline $\begin{array}{l}\text { Cyclonic } \\
\text { Storm }\end{array}$ & 59 & 24 & 35 & 25 & 40 & 4 & 89 & 24 & 114 & 20 \\
\hline $\begin{array}{l}\text { Severe } \\
\text { cyclonic } \\
\text { storms }\end{array}$ & 42 & 19 & 5 & 17 & 16 & 2 & 38 & 11 & 63 & 15 \\
\hline
\end{tabular}

The highest number of severe cyclones occurs in November in BOB with an average of one per year. These cyclones usually hit the eastern coast of India and extend to Bangladesh, Myanmar and even to part of South East Asia ( Figure 5) . On the average 1-2 tropical cyclones do form over the Arabian Sea each year, but few of these storms are intense enough to be classified as very severe.

\subsection{Destruction caused by a few severe TC over Indian Ocean:}

\section{(i) Bhola cyclone of $\mathbf{1 9 7 0}$}

It formed in November 8, 1970 at the BOB [Figure 7(a)] and travelled north, intensifying sustained wind to $185 \mathrm{~km} / \mathrm{h}$ and eye pressure of $986 \mathrm{hpa}$ on November 12, to reach category 3 states in the SSHS. It made landfall over Bhola island, Bangladesh (East Pakistan at that time), in the evening of November 12, coinciding with the time of local high tide. The cyclone caused heavy and wide spread rain mainly in Port Blare and North East part of India.

Almost 500,000 people lost their lives in the storm, primarily as a result of the storm surge that flooded much of the low-lying islands. The MV Mahajagmitra, a 5,500-ton freighter en route from Kolkata to Kuwait, was sunk by the storm on November 12, all 50 people on board lost their life. 


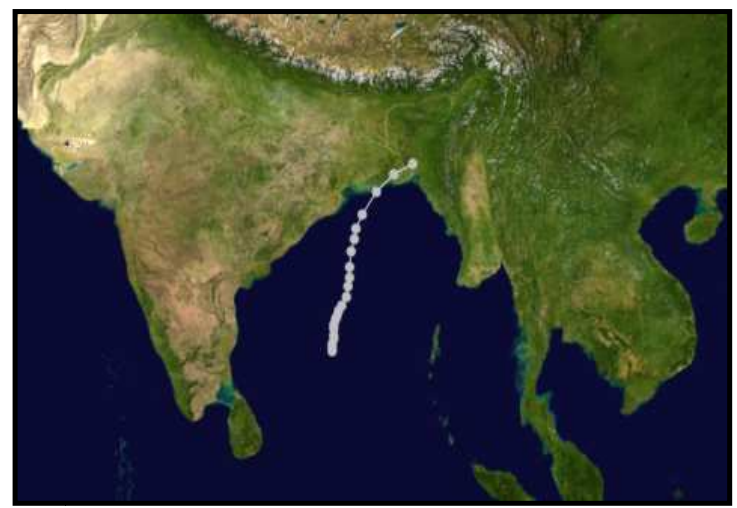

Fig.ure 7(a). Track of TC Bhola, developed at BOB in November 1970

\section{(ii) 1991 Super cyclone : BOB 01}

The 1991 super cyclone developed as a tropical depression on April 22,1991 in the BOB. The wind speed then started to increase to reach a tropical storm status on April 24 and it strengthened itself while moving towards northwest.

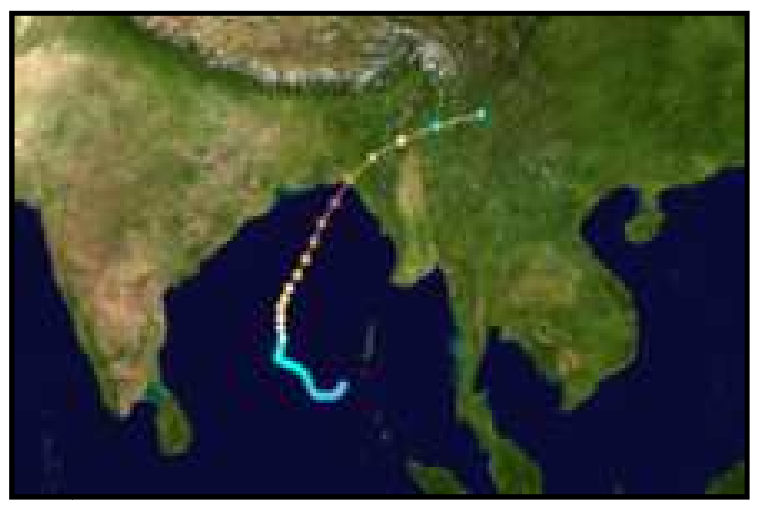

Figure 7(b ). Track of Super Cyclone BOB01 of April 1991

As the cyclone moves through a high pressure system to its northwest and east, the mid-level westerlies steered its direction to northeastward. Due to enhanced upper level outflow by the westerlies, and warm water bodies of BOB, the cyclone strengthened itself on April 28. The wind speed increased further to $250 \mathrm{~km} / \mathrm{h}$ with 
lowest pressure of 918 mbar making this a Category 5 TC on April 29 and it made landfall in Bangladesh causing damage to East and NE part of India . Total fatality comes to 1, 40,000 and estimated damage was put at US\$1.7 billion.

\section{(iii) Super cyclone 1999}

A Tropical Depression formed in October 25, 1999 over the Malay Peninsula was steered northwestward under the influence of the subtropical ridge. On reaching warm water bodies of BOB and a favorable upper level winds it strengths to become a Tropical Storm on October 26 around $345 \mathrm{~km}$ south-southwest of Myanmar. The storm continued to strengthen and moved in the same direction, intensified to a peak of $260 \mathrm{~km} / \mathrm{h}$ winds, to fall in category 5 cyclones on October 28, and it hit the Indian state of Orissa near the city of Bhubaneswar on October 29. The system was the first storm to be given the new meteorological label "super cyclonic storm" by the India Meteorological Department (IMD). The cyclone re-emerged into the BOB on October 31, and dissipated in November 3 over the open water as is seen in Figure 7(c).

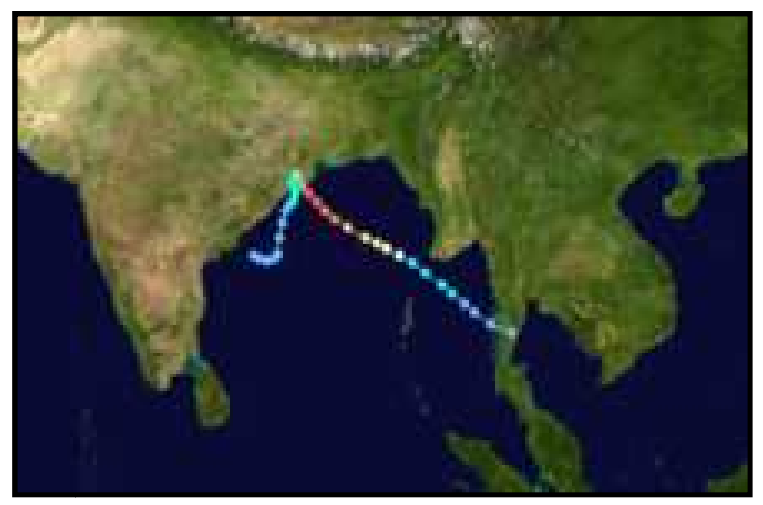

Figure 7(c) Track of super cyclone 1991

The storm surge being 26 feet ( 8 meters), it caused record breaking floods accompanied by heavy rain in Orissa that caused damage to $17,110 \mathrm{~km}^{2}$ of crops , uprooting 90 million trees . About 10,000 people lost their life with 1.67 million people rendered homeless.

\section{(iv) TC of North Indian Ocean causing devastation to neighboring countries}

A large number of TCs develop in the Indian Ocean cause devastation to neighboring countries. One of such very strong cyclones is the Nargis, the first named event in Indian Ocean that developed on April 27, 2008 in the 
central BOB (Figure 8). It started with a northwestward track and moved eastward where it met the favourable condition of the BOB to intensify and attained peak wind speed of $165 \mathrm{~km} / \mathrm{h}$ to form a Category 4 cyclone on May 2. The cyclone made landfall in the Myanmar bringing worst natural disaster in its living memory, caused damage estimated at over $\$ 10$ billion and at least 146,000 people lost their lives. A few scenario captured during this deadly cyclone (Figure 9) could give the magnitude of devastation.

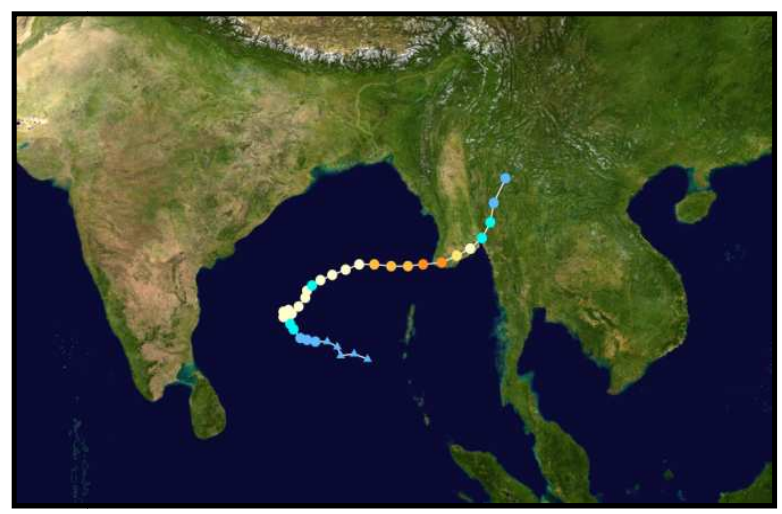

Figure .8 . Track of the TC Nargis, April -May 2008
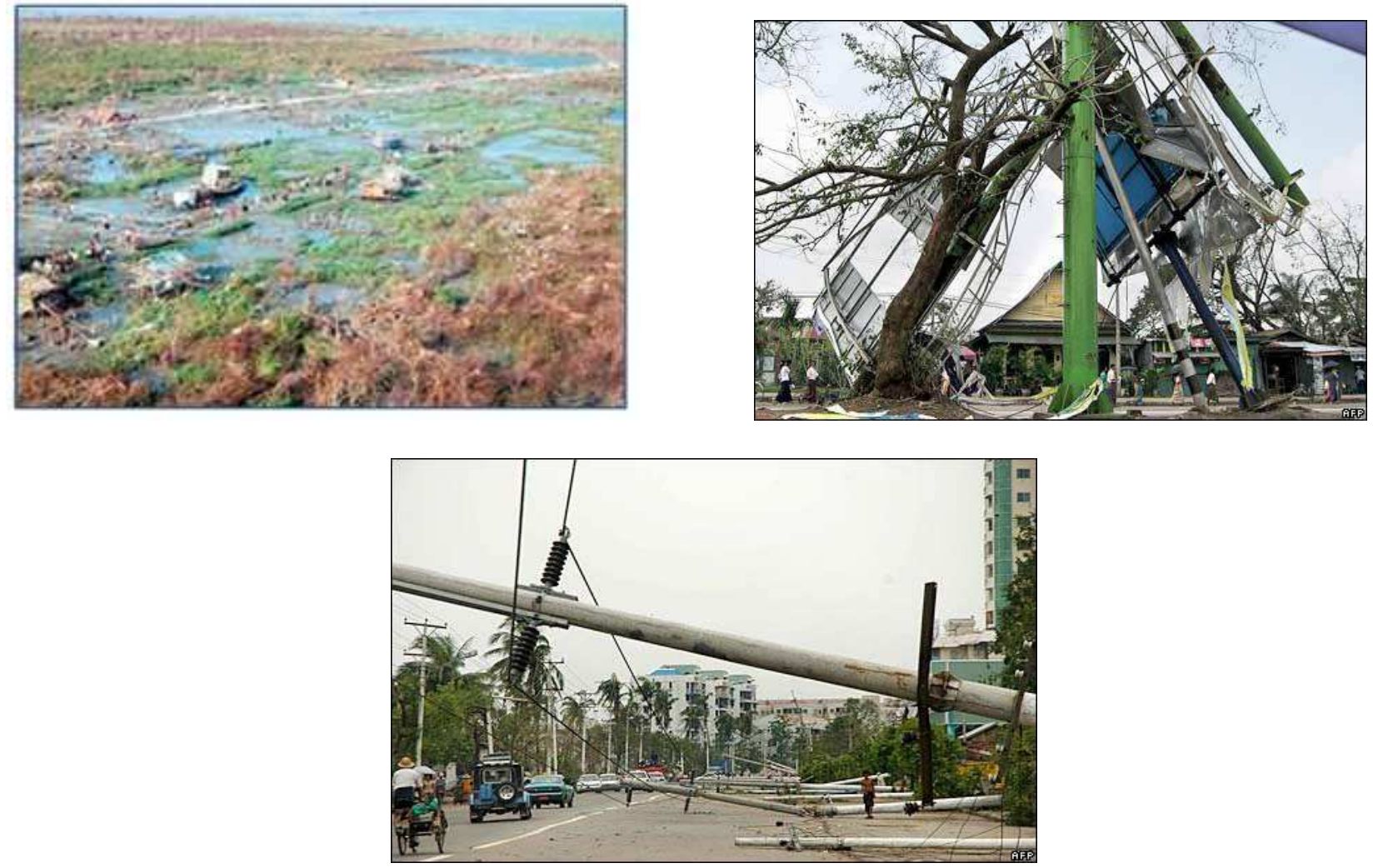

Figure .9 . A few devastating scenes caused by the Nargis in Myanmar www.sln.org.uk/geography/Documents/Presentations/Cyclone Nargis.ppt 
Unlike in BOB only afew cyclones over ARB can be classified as very severe [Amato and Suzana 2011]. One of the strongest cyclones in the ARB is Gonu, developed in the area of convection in the eastern Arabian Sea on June 1, 2007 (Figure 10). It intensifies as it moves in northwest direction due to a favorable upper-level environment to attain peak wind speed of $240 \mathrm{~km} / \mathrm{h}$ on June 3 . It however weakens on encountering dry air and cooler waters on June 6, it made landfall on the eastern-most tip of Oman . It further progresses northward through Gulf of Oman to dissipate on June 7 after making landfall in southern Iran. The cyclone causes significant damage to Oman, along with United Arab emirates, Iran and Pakistan with no causalities in the Indian coastal region. The estimated fatalities come to around 78 with total damage of US \$44.4Billion. One of the damage scenes in Oman is shown in Figure 11.

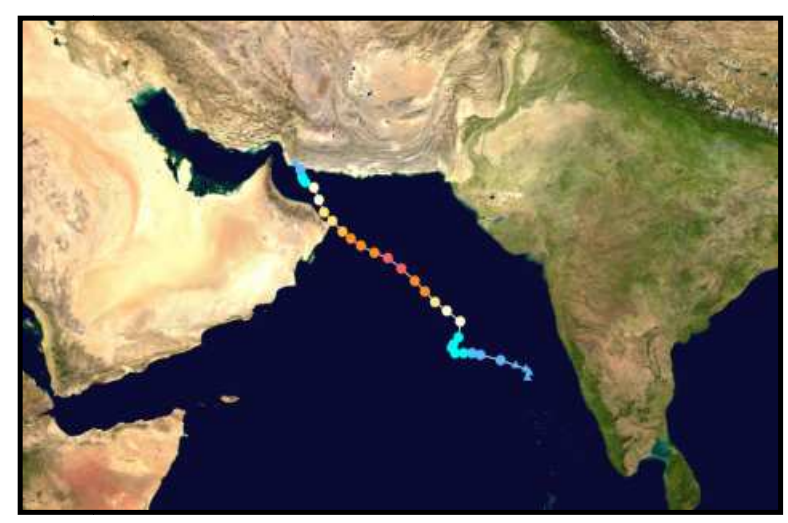

Figure 10. Track of Cyclone Gonu, June 2007

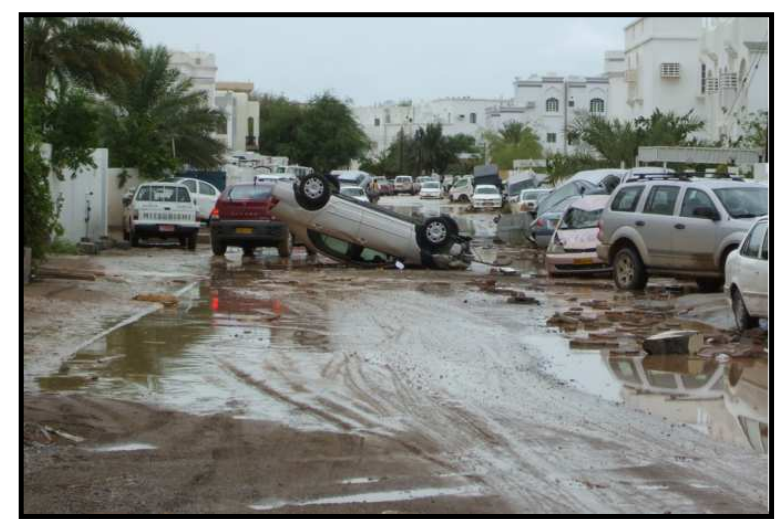

Figure 11. Flodding and twisting of car caused by Gonu in Oman road 


\section{Discussions}

The question is why the TCs that affect south Asia and surroundings do develop mainly in the BOB. A few required conditions that favor the formation of TC are: low pressure at the surface, availability of large volume of moist air for formation of convective situation in the atmosphere, relatively high ocean surface temperatures exceeding $26^{\circ}-27^{\circ} \mathrm{C}$ and practically no wind shear i.e. the wind speed and direction should not rapidly change over a short distance in the atmosphere both in altitude and horizontal direction. Amongst all these conditions, the higher temperature of BOB compared to that of ARB provides a favourable energy situation for TC formation through intense evaporation from warm water surface. The moist water that forms cloud in this process, releases latent heat, thereby adding more energy input in the growth and development of a cyclone. Further, cyclonic surge depends on coastal geometry; a curved basin can shift the surge position and also could increase its peak value. The BOB coast structure satisfies these condition along with this the shallow coastal ocean topography and the special features of tide in the region provide inputs for formation of TC. Contrary to this structure and environment , the coast of ARB, shared by Yemen, Oman, Iran, Pakistan, Sri Lanka, Maldives and Somalia, the geometry is relatively curve free.

\subsection{Programmes taken up for early warning on TC}

The tropical cyclone Nargis which hit Myanmar in 2008 is a landmark fatal event for the birth of a series of programmes formulated for early warning on growth and arrival of a TC. It was initiated by WMO, in consultation with UNESCO, in its 60th Executive Council session in 2008 through a plan to establish a Storm Surge Watch Scheme in all five tropical cyclone basins.

Along with such scheme, installation of a number of Radio Detection and Ranging (RADAR) system by Government of India mainly along the coastal regions have now improved in prediction warning to the people on the approach of a TC . A radar echogram (Figure 12) (http://www.imd.in) shows how the approach and development of a TC is detected in its screen. This is a composite picture of number of cyclones occurred at BOB. High resolution radar and Automatic Weather Station (AWS) are installed for receiving weather parameters with high temporal and spatial resolutions. 


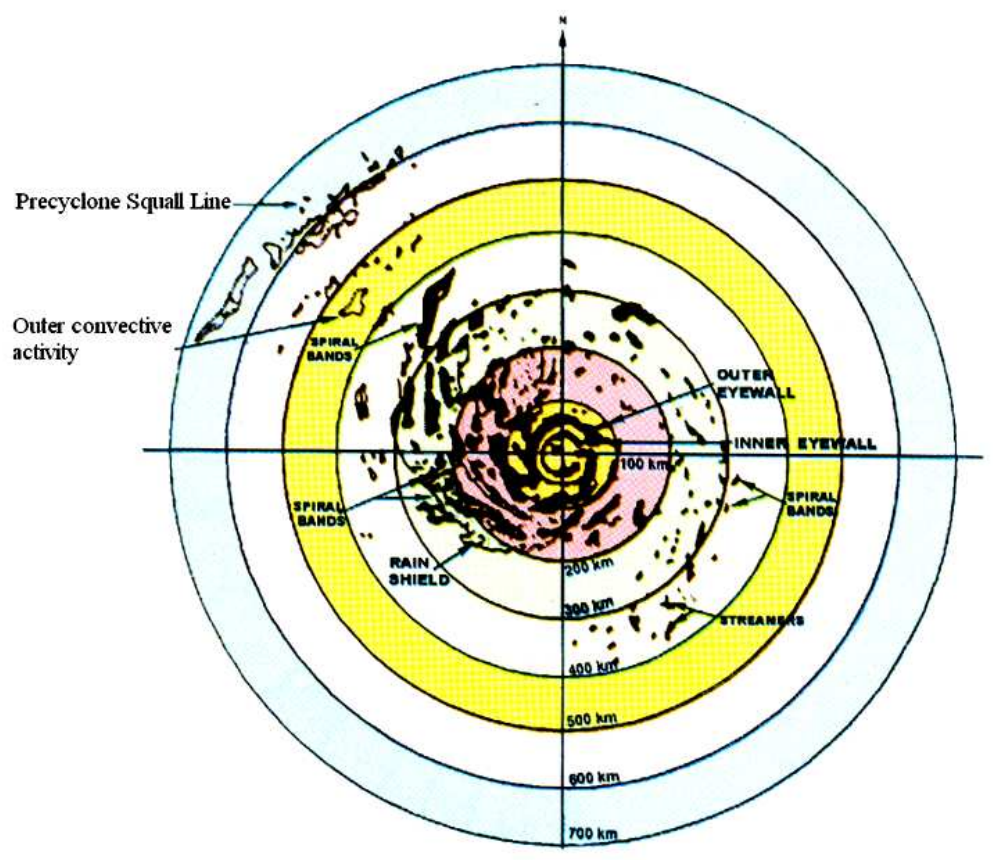

Figure 12 .Radar echogram shows development of TC and its eye . A composite picture of number of TCs occurred at BOB. ( Source: FAQ, national Hurricane centre USA)

Further, the growth and development of a TC could be monitored and predicted through mapping of wind pattern and rain magnitude from satellite data and numerical models. From Figure 13(a), one can see how wind pattern from numerical model Varsha could offer prediction on growth and movement of the SIDR (a BOB cyclone, see table III) of November 2007. Wind pattern observed from NOAA satellite [Figure 13(b) ] also offers a means of prediction of a cyclone and its course of movement. The impact of a TC on precipitation even at far off places from its landfall area is also a serious hazard (Devi et al 2013). One such case is presented for Aila TC that strike Bangladesh shore on May 25 [Figure 14(a)]. The model predicted rain Figure 14 (b) and satellite TRMM (Tropical Rain Measuring Mission) derived precipitation [Figure 14(c)] observed precipitation shows that Aila brought heavy rain to NE part of India, a location away from direct hit zone of the cyclone . 

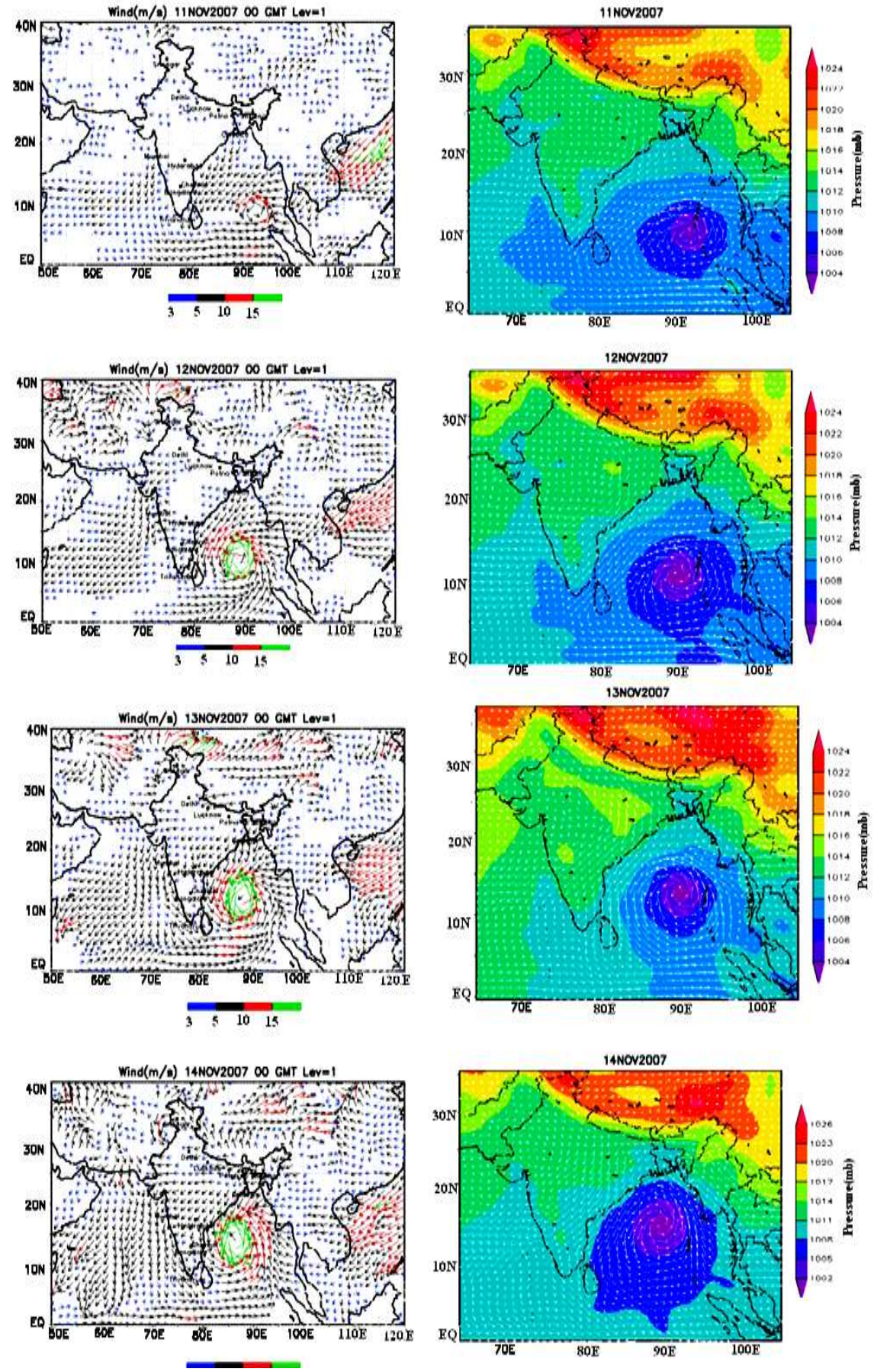

Figure 13 (a) Prediction of wind pattern from numerical model Varsha and (b) NOAA satellite observed wind prior to SIDR cyclone of November 2007 . Note the development and movement of the TC 

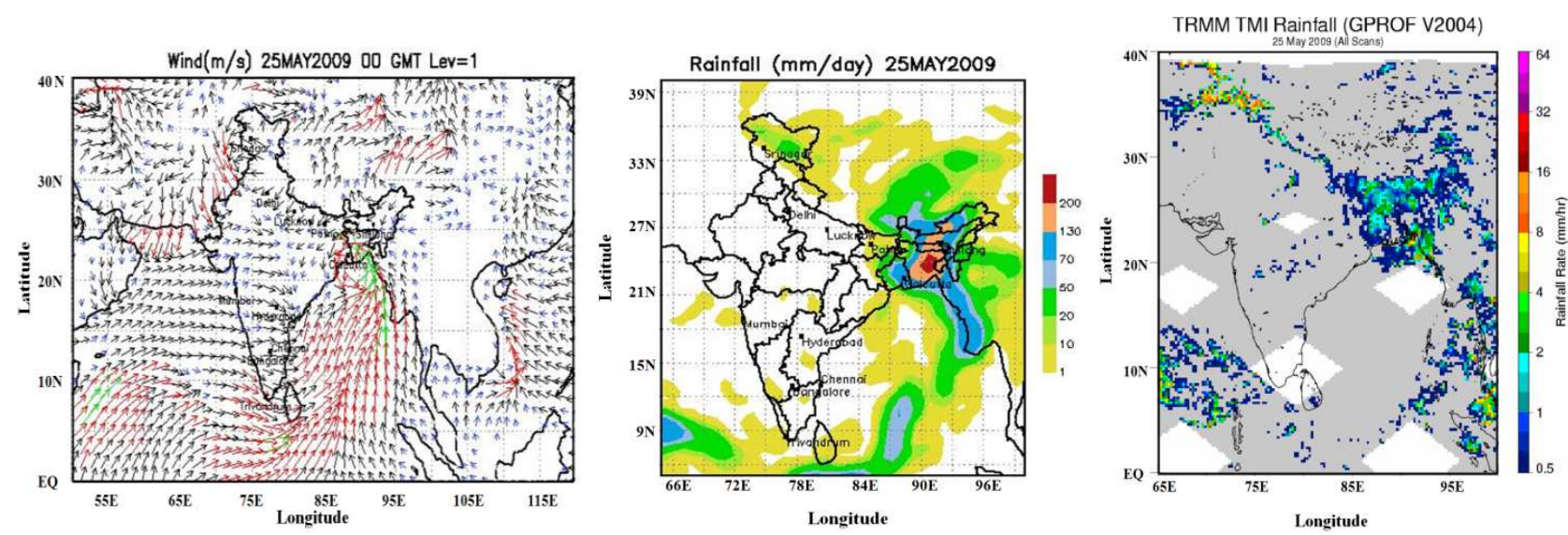

Figure 14. (a) Model predicted wind pattern showing cyclone Aila to strike Bangladesh shore on May 25 , 2009 , (b) the predicted precipitation by Aila in NE region and (c ) the observed precipitation by TRMM.

\section{2 precautionary measures}

Storm surges, torrential rain and extremely powerful winds associated with TC are the major natural hazards of the modern time. The impact of a TC in its hit areas is so strong that the social structure in these location may get changed forever [Pielke et al., 1997]. With the advancement of technology and state of art equipments, the national and international agencies are though able to provide precautionary warning to the people of the approach of a TC, but still impossible to control it .

There were however attempt to dissipate growth of a TC by seeding with silver iodide or freezing super cool water at the outer edge of the circulatory structure of the cyclonic cloud so that the process would consequently collapse its eye, thereby decreasing the wind speed. This experiment tried with hurricane Debbi showed that with initial slow down of its growth, it regained its strength after each of two seeding forays. There were also earlier such attempt in 1947 but the result proved to be disastrous when the hurricane immediately changed its course after being seeded, and caused havoc to Georgia, instead of Florida, the threatened location .There are other suggestions for dissipating energy of a TC by cooling the water of ocean through dumping of icebergs or dropping large quantities of ice into the eye at the very early stages of development. Suggestions are also forwarded on use of nuclear weapon for tearing apart the formation of the eye. However, these ideas seem to be far from realistic. 
It is also equally important that the positive role played by a $\mathrm{TC}$ in maintaining a delicate global climatic balance through transfer of heat from the equator to pole ward needs to be highlighted. Disruption of this balance by any artificial method will bring drastic modification to already sensitive climatic scenario. This may raise Sea Surface Temperature (SST) to a critical level favoring generation of TC with super energy which may cause unimaginable havoc and destruction. Thus any attempt in modifying natural phenomena may cast negative effect to all global communities.

Therefore, it is important that more attention be paid for reducing loss of life and property during such events especially in the coastal region. The Cyclone Thans ( Figure 15) displays some scenario in the southern state of India, it wiped out thatched house at the coastal region [Figure 16(a)] and loss of property and erosions in the environment [Figure 16(b) and Figure 16(c)]. The initiative taken by Government of India in the construction of coastal durable housing in has proved to be an effective . The hazard warning services provided by Government of India through mobile and internet especially to fisher man have reduced the fatality rate. In this respect the Global Earth Observation System of Systems (GEOSS), is bringing the globe into a frontier where comprehensive, integrated data sets from many thousands of individual Earth observation technologies around the globe are made available for in depth understanding of Earth's complex system dynamics which will offer improvement in predictability of such natural hazards .

It is most essential for those living around TC affected areas to keep oneself alert by monitoring the weather condition through relevant communication media and to take necessary measures in advance before the devastation starts.

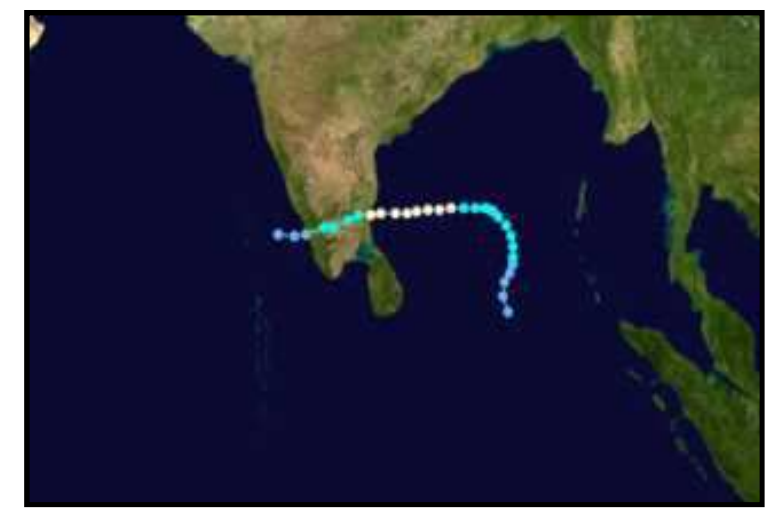

Figure 15 . Track of Cyclone Thane, December 2011 -January 2012 


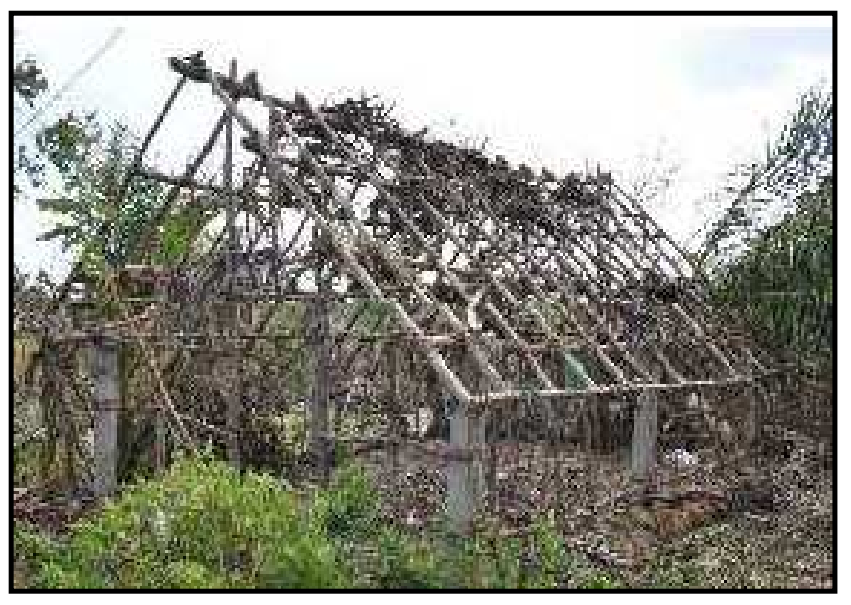

(a)

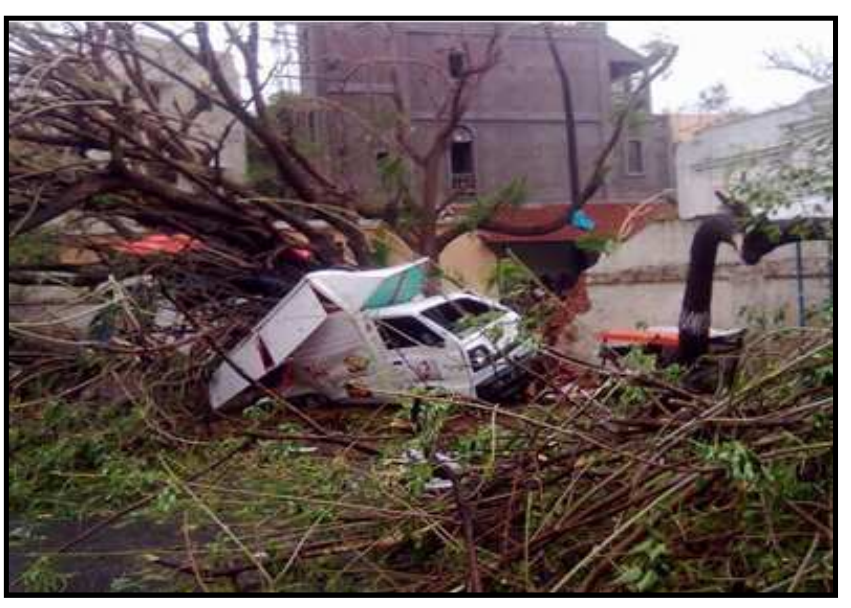

(b)

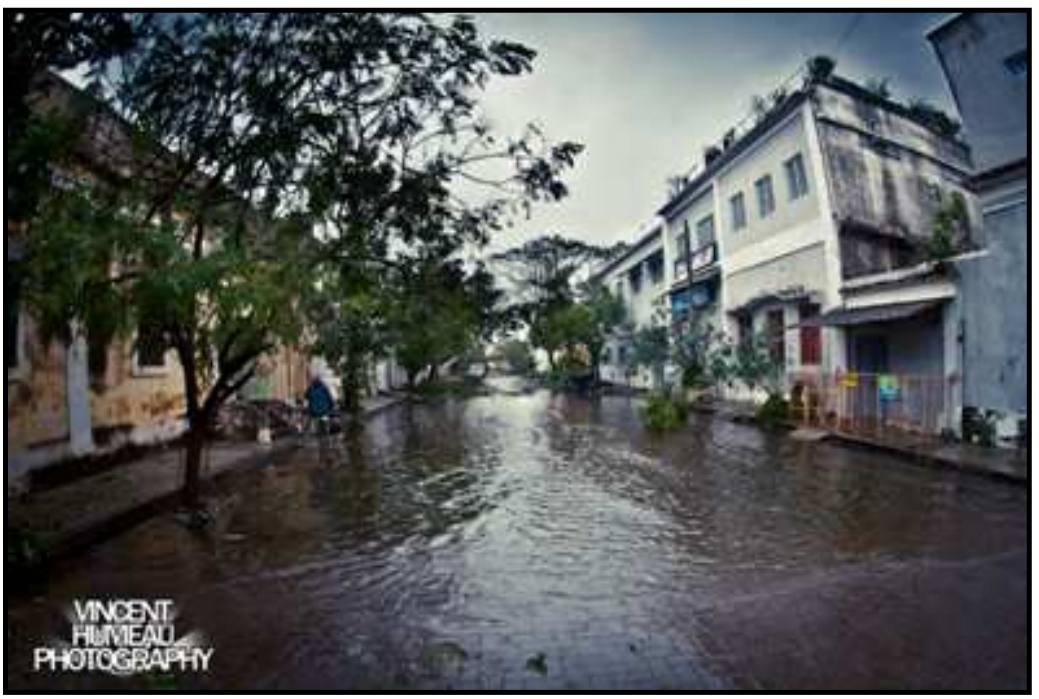

( c )

Figure 16. Destruction caused by Tropical Cyclone Thane (a) Collapse of Thatched house (b) Total destruction of property and (c) Erosion of environment. Source: Community Collective Society For Integrated Development (CCFID), 80, 2nd street, Seetharamnagar, Cuddalore -607001. 


\section{References}

Dube, S. K ., Rao, A. D., Sinha , P .C., and Bahulayan, N, Storm surge in the Bay of Bengal and Arabian Sea: the problem and its prediction . Mausam, 48 ,2, 283-304, 1997.

Chandrasekhar, A. , 2010, Basics of Atmospheric Science ,in Factors responsible for the for,aion of Tropical Cyclone pp. 300-311 (PHI learning PVT Ltd, New Delhi publication )

Devi, Minakshi., Kalita , Santanu., Das, Subrat ., Goswami, Hirak ., Barbara, Ananda. Kumar ., Prediction of cyclonic tracks over Bay of Bengal and resultant precipitation in the north-east region. , Geomatics, Natural Hazards and Risk . http://www.tandfonline.com/loi/tgnh20, 2013

Amato, Evan., Suzana, T., Camargo, J., A Climatology of Arabian Sea Cyclonic Storms. J. Climate, 24, 140-158, 2011.

Gray, W. M., Global view of the origin of tropical disturbances and storms, Mon. Wea. Rev.96, 669-700. 1968.

NOAA Tropical cyclones of the North Atlantic 1871-1998 Historical Climatology series 6-2, (US. department of Commerce, National climatic Data Centre) 1999, pp 206.

Pielke, Jr. R. A., Pielke, Sr. R.A., 1997, Hurricanes. their Nature and Impacts on Society. (John Wileynd Sons, Chichester, New York).

Singh, O. P., Khan, Ali., Masood, Tariq ., and Rahman, Md. Sazedur., Has the frequency of intense tropical cyclones increased in the north Indian Ocean? CURRENT SCIENCE, 80, NO. 4, 25 575-580, 2001 